\title{
PEMBINAAN KOMPETENSI DOSEN JURUSAN PENDIDIKAN LUAR SEKOLAH MELALUI COACHING CLINIC PENULISAN ARTIKEL ILMIAH
}

\author{
Fauzi Kurniawan, Nurlaila, Faber Simorangkir* \\ Surel :fauzi_k50@yahoo.com
}

\begin{abstract}
The type of this study is quantitative research with a pre-test and post test design. The data were collected through questionnaire method. Hypothesis test was done by using $t$ test to test the existence of difference and Anova test to see the improvement of ability of the research sample that is to know the difference of ability (knowledge and skill) of PLS lecturer in producing scientific articles published in accredited national journals and reputable international journals through coaching clinic. The population in this study is all lecturers majoring outside of FIP Unimed Education. Sampling was done randomly by looking at the lecturers' teaching activity, research and scientific articles writing from their research results to the journal. Based on the statistical results, it can be seen that the minimum pre-test value were obtained 70,00 by LSL Lecturer before joining coaching clinic and the maximum value was 73,00. The average value obtained was 71.25 with a standard deviation value was 1.21. While the post test value obtained after the PLS lecturer joined the coaching clinic starting from the material in the classroom to the speker's guidance, then the minimum value obtained was 74.00 and the maximum value was 85.00. The average value obtained was 80.41 with 3.11 standard deviation. While at the calculation of $t$ Test were obtained a statistical value that $t$-calculate $=-12.61$; while $t$ Table, ie $t d f=11 ; A=0.05=2.20$. This means that $t>t d f=29 ; A=0.05$. Thus, it can be said that these two average values statistically are significantly different. It means that in the post-test, the average value obtained by PLS Lecturer after attending the coaching clinic was higher than the average score obtained by the lecturer before attending the coaching clinic. Therefore, it can be argued that in addition to improving the ability in writing scientific articles, the implementation of coaching clinic can help PLS Lecturers to improve thinking, analyzing, writing and reviewing skill thus it can increase the quantity and quality of writing scientific articles to be published in the accredited journal.
\end{abstract}

Keywords: coaching clinic, scientific articles, competence

\section{PENDAHULUAN}

\footnotetext{
*Fauzi Kurniawan,S.Psi.,M.Psi. Dosen Jurusan PLS FIP Unimed

*Dr.Nurlaila,M.Pd. Dosen Jurusan PLS FIP Unimed

*Drs.Faber Simorangkir,MS. Dosen Jurusan PLS FIP Unimed
} 
$\mathrm{S}$ alah satu tugas penting dalam menjalankan fungsi Tridharma Perguruan Tingg yang dilakukan dosen adalah melaksanakan penelitian kemudian mempublikasikan hasil penelitian tersebut agar bermanfaat bagi orang lain. Kinerja jurusan, fakultas dan perguruan tinggi salah satunya dipengaruhi oleh kuantitas dan kualitas dari publikasi ilmiah yang dihasilkan dosen. Dari data peneliti yang terdaftar di badan Lembaga Ilmu Pengetahuan Indonesia (LIPI) tercatat jumlah peneliti saat ini hanya sekitar 9.000 orang, baik secara kuantitas maupun kualitas jumlah penelitian di Indonesia masih belum memuaskan di tingkat global, hal ini diukur dari rendahnya jumlah artikel yang dipublikasikan dalam jurnal internasional.

Tuntutan publikasi yang dilakukan dosen / tenaga pendidik di perguruan tinggi dapat memberikan dampak yang cukup besar terhadap perkembangan ilmu pengetahuan dan peningkatan kesejahteraan masyarakat sehingga perlunya kesadaran dosen / tenaga pendidik untuk melakukan penelitian / menulis karya ilmiah. Salah satu cara yang dilakukan pemerintah dalam upaya mengembangkan kemampuan menulis karya ilmiah di lingkungan perguruan tinggi adalah memberlakukan regulasi yang mewajibkan setiap dosen untuk menulis artikel di jurnal ilmiah sebagai salah satu prasyarat kenaikan pangkat dan memperoleh gelar akademik lainnya. Oleh karena itu, dosen tentunya semakin dituntun untuk aktif menulis di jurnal ilmiah baik tingkat nasional terakreditasi maupun jurnal internasional bereputasi.

Merujuk Peraturan Menteri Pendayagunaan Aparatur Negara dan Reformasi Birokrasi (PAN RB) Nomor 17 Tahun 2013 dan Peraturan Menteri Riset, Teknologi dan Pendidikan Tinggi Nomor 92 Tahun 2014 tentang kenaikan jenjang jabatan akademik dosen yang mewajibkan untuk publikasi pada jurnal ilmiah nasional terakreditasi dan jurnal internasional bereputasi di bidangnya. Kebijakan ini memiliki tujuan agar publikasi ilmiah jabatan fungsional dosen di Indonesia dapat ditingkatkan. Adapun tujuan dari publikasi ini adalah mensosialisasikan hasil temuan dari kajian atau penelitian berdasarkan evidence (bukti /fakta/ data) di lapangan baik di tingkat lokal, nasional, regional maupun internasional. Banyak fakta hasil kajian dan penelitian yang sebetulnya sangat penting dan menarik untuk diakses dan dijadikan bahan yang sangat penting untuk pengambilan keputusan tetapi sulit untuk diperoleh/diakses/dijangkau oleh pengambil kebijakan/ pihak pengguna lain karena tidak dipublikasikan secara luas.

Jurnal online maupun cetak menjadi sarana yang sangat baik 
untuk mempublikasikan hasil penelitian pada lingkup yang lebih luas. Hal ini diharapkan selain dapat meningkatkan reputasi para penulis, juga diharapkan dapat menjadi wahana pengembangan ilmu pengetahuan. Namun data menunjukkan bahwa dosen memiliki semangat dan komitmen yang rendah dalam menulis dan mempublikasikan hasilpenelitian mereka melalui jurnal terbitan berkala ilmiah, hal ini dapat disebabkan antara lain kemampuan menuliskan dalam artikel ilmiah, pengembangan budaya menulis maupun motivasi untuk menulis yang masih rendah pada dosen / tenaga pendidik.

Dengan kondisi tersebut, maka Jurusan Pendidikan Luar Sekolah (PLS) akan mengadakan Coachingclinic penulisan artikel ilmiah ke jurnal bagi Dosen Pendidikan Luar Sekolah FIP Unimed dengan harapan agar para dosen dapat aktif membuat jurnal dan mempublikasikan hasil penelitiannya sehingga publikasi artikel ilmiah dosen jurusan PLS di jurnal nasional dan internasional dapat meningkat.

\section{METODE PENELITIAN}

\section{Rancangan Penelitian}

Adapun jenis penelitian ini adalah penelitian kuantitatifyang penekanannya pada numerical (angka).Penelitian ini merupakan penelitian dengan rancangan pemberian kuesioner.Penelitian kuantitatif merupakan penelitian yang banyak menuntut penggunaan angka, mulai dari pengumpulan data, penafsiran terhadap data, seta penampilan dari hasilnya.

Menurut Sugiyono (2012) metode penelitian kuantitatif dapat diartikan sebagai metode penelitian yang berlandaskan pada filsafat positivism yang digunakan untuk meneliti pada populasi atau sampel tertentu. Teknik pengambilan sampel dapat dilakukan secara random, pengumpulan data menggunakan instrumen penelitian, analisis data bersifat kuantitatif/statistik dengan tujuan untuk menguji hipotesis yang telah ditetapkan.

\section{Lokasi Penelitian}

Lokasi penelitian ini dilakukan di Jurusan Pendidikan Luar Sekolah (PLS) Fakultas Ilmu Pendidikan Unimed

\section{Populasi Penelitian}

Populasi dalam penelitian ini yaitu Dosen jurusan PLS FIP Unimed yang masih terdaftar di jurusan PLS yang berjumlah 13 orang

\section{Teknik Pengumpulan Data}

Data dikumpulkan melalui metode dokumentasi dan kuesioner. Metode dokumentasi digunakan untuk memperoleh data daftar nama, 
jumlah dosen dan jumlah karya tulisan yang dihasilkan dosen. Sedangkan metode kuesioner digunakan untuk memperoleh data mengenai kemampuan dosen dalam menulis artikel ilmiah setelah mengikuti Coaching Clinic.

\section{Teknik Analisa Data}

Penelitian ini menggunakan metode kuantitatif dengan menggunakan kuesioner untuk melihat peningkatan kompetensi dosen setelah mengikuti coaching clinic. Kuesioner adalah daftar pertanyaan yang diberikan kepada orang lain yang bersedia memberikan respon sesuai dengan permintaan pengguna. Kuesioner merupakan teknik pengumpulan data yang dilakukan dengan cara memberi seperangkat pernyataan secara tertulis kepada responden untuk dijawab (Sugiyono, 2005).

Kuesioner adalah suatu teknik pengumpulan informasi yang memungkinkan analis mempelajari sikap, keyakinan, perilaku, dan karakteristik beberapa orang di dalam organisasi yang bisa terpengaruh oleh sistem yang diajukan oleh sistem yang sudah ada.Kuesioner adalah daftar pertanyaan yang disiapkan oleh peneliti dimana tiap pertanyaan berkaitan dengan masalah penelitian. Kuesioner tersebut pada akhirnya diberikan kepada responden untuk dimintakan jawaban. Analisis data yang dilakukan dengan menggunakan analisis kuantitatif dengan menggunakan program SPSS versi 20.00

\section{HASIL DAN LUARAN YANG DICAPAI}

\section{Pemilihan Obyek Penelitian}

Aktifitas pertama yang dilakukan dalam penelitian kuantitatif ini yaitu menentukan populasi penelitian. Kemudian dari populasi penelitian ditentukansampel penelitian. Adapun jumlah dosen PLS saat ini berjumlah 13 orang, namun yang dipilih sebagai sampel penelitian berjumlah 10 orang yaitu Dosen Jurusan PLS yang aktif melakukan penelitian dan menulis karya ilmiah / jurnal sesuai bidang ilmu dan keahliannyaberdasarkan jumlah penelitian dan publikasi yang dilakukan di jurnal nasional setiap tahunnya. Dari sampel penelitian tersebut akan diberikan coaching clinic tentang penulisan artikel ilmiah.Proses perhitungan pengetahuan dan kemampuannya dalam menulis artikel ilmiah sebelum dan setelah mengikuti coaching clinicakan diukur sebelum coaching clinic dengan pre-test kemudian diakhiri dengan post-test.

\section{Pelaksanaan Pre-Test}

Pelaksanaan pre-testdilakukan terhadap sampel penelitian dengan jenis kuesioner/pertanyaan yang sama. Soal pre-test ini berbentuk 
pernyataan sikap dengan 5 pilihan menggunakan skala likert. Jumlah pernyataan sebanyak 20 butir dengan durasi waktu mengerjakan 30 menit. Bobot untuk setiap butir soal sama yaitu dari skor 1-5. Jadi, nilai maksimum yang diperoleh dosen dengan total skor $100 /$ ratarata 5. Kemudian hasil pre-test tersebut diperiksa dan berdasarkan hasil pemeriksaan tersebut dicari: nilai terendah, nilai tertinggi, dan nilai rata-rata. Kemudian, dengan menggunakan nilai rata-rata tersebut dilakukan uji perbedaan nilai ratarata untuk mendapatkan kepastian perbedaan antara pretes dan post test.

\section{Pelaksanaan Coaching Clinic}

Setelah dilakukan pre-test, kemudian dosen PLS FIP Unimed mengikuti kegiatan Coaching Clinic dengan materi mengenai teknik penulisan artikel ilmiah ke jurnal. Durasi kegiatan Coaching Clinic dilakukan selama 4 jam di kelas yang diikuti oleh dosen PLS kemudian dilanjutkan bimbingan secara online melalui email,, telepon dan Whatsapp kepada instruktur / pemateri setelah dosen selesai mengikuti coaching clinic sampai menghasilkan artikel ilmiah yang akan disubmit ke jurnal.

\section{Pelaksanaan Post-Test}

Sama halnya seperti pada pretest, post-test pada penelitian ini juga dilakukan terhadap sampel penelitan dengan materi, jumlah, dan pilihan pertanyaan yang sama. Post test diberikan setelah dosen PLS selesai mengikuti coaching clinic berupa materi di kelas yang disampaikan oleh pemateri Prof. Dr. Ibnu Hajar, M.Si sampai kegiatan bimbingan secara online dengan instruktur mengenai cara, metode dan kendala yang dihadapi sampai tulisannya diterbitkan di jurnal terakreditasi.

Pertanyaan pada instrumen post-test juga diberikan sebanyak 20 butir dengan durasi waktu mengerjakan 30 menit. Bobot untuk setiap butir soal sama yaitu dari skor 1-5. Jadi, nilai maksimum yang diperoleh dosen adalah dengan total nilai 100 / rata-rata 5. Hasil post-test kemudian diperiksa dan dilakukan perbandingan: nilai terendah, nilai tertinggi, dan nilai rata-rata. Untuk nilai rata-rata kemudian dilakukan uji hipotesis untuk penarikan kesimpulan apakah kegiatan coaching clinic dapat meningkatkan pengetahuan dan kemampuan dosen jurusan PLS FIP Unimed dalam menulis artikel ilmiah pada jurnal nasional maupun internasional.

\section{Analisis Hasil Pre-Test}

Pre-test dilakukan untuk mengetahui kemampuan yang dimiliki dosen dalam proses penulisan artikel ilmiah yang dapat diterbitkan pada jurnal nasional maupun internasional yaitu berupa kemampuan berpikir, kemampuan 
menganalisis, kemampuan menulis dan kemampuan mereview. Rangkuman hasil analisis nilai pretest disajikan pada tabel berikut.

Tabel 1. Descriptive Statistics Pre-Test

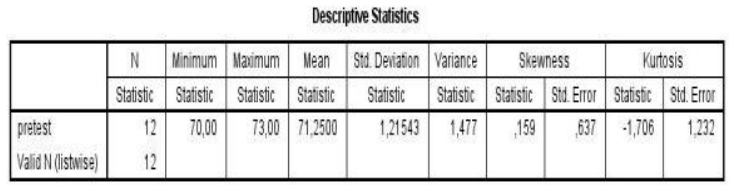

Pada tabel diatas dapat dilihat bahwa pada saat pre-test, nilai minimum yang diperoleh untukkelas dosen PLS sebelum mengikuti coaching clinic penulisan artikel ilmiah yaitu 70, sedangkan nilai maksimum sebesar 73. Nilai mean untuk kelas dosen PLS sebelum mengikuti coaching clinic sebesar 71,25 dengan nilai statistik standar deviasi sebesar 1,15

\section{Analisis Hasil Post-Test}

Setelah dilaksanakan proses coaching clinic dengan pemberian materi di kelas tentang teknik penulisan artikel ilmiah kemudian dilanjutkan dengan bimbingan online (melalui email, telepon atau WhatsApp) mengenai progress, hasil maupun kendala yang dihadapi selama penulisan sampai terbitnya jurnal penelitian Dosen PLS, maka dilakukan post test untuk mengetahui kemampuan yang dimiliki Dosen PLS dalam menghasilkan artikel ilmiah. Setelah pelaksanaan post-test maka dilakukan analisis terhadap hasil post-test. Perhitungan hasil analisis nilai post-test dapat dilihat pada rangkuman hasil analisis nilai posttest dosen PLS berikut.

Tabel 2. Descriptive Statistics Post-Test

Descripine Statistics

\begin{tabular}{|c|c|c|c|c|c|c|c|c|c|c|}
\hline & N & Inimum & Haimum & Meno & \$t10. Deididin & Varianer: & \multicolumn{2}{|c|}{ Stemess } & \multicolumn{2}{|c|}{ Kuthoss } \\
\hline & Satistit: & Shisisic & Stabisic & Statistic & Statistit & Stetistic & Sitst: & Sti. Eror & Statistic & SWL Eror \\
\hline $\begin{array}{l}\text { postest } \\
\text { Varian (istived) }\end{array}$ & 12 & 74,00 & 86,00 & 80,4167 & 311764 & 9720 & .725 & 637 & 196 & 1,232 \\
\hline
\end{tabular}

Pada tabel diatas dapat dilihat bahwa pada saat post-test, nilai minimum yang diperoleh untukkelas Dosen PLS setelah mengikuti coaching clinic penulisan artikel ilmiah yaitu 74 , sedangkan nilai maksimum sebesar 85 . Nilai mean untuk kelas Dosen PLS setelah mengikuti coaching clinic sebesar 80 dengan nilai statistik standar deviasi sebesar 3,11.

\section{ANALISIS HASIL PRE-TEST DAN POST-TEST}

Setelah dilaksanakannya proses coaching clinic untuk mengetahui kemampuan berpikir, kemampuan menganalisa, menulis dan mereview pada Dosen PLS maka dilakukan analisis perbandingan hasil pre test dan post-test. Perhitungan hasil analisis nilai pre test dan post-test dapat dilihat pada rangkuman hasil analisis dosen PLS berikut ini.

Tabel 3.Descriptive Statistics PreTestdan Post Test

Descipitive Statisics

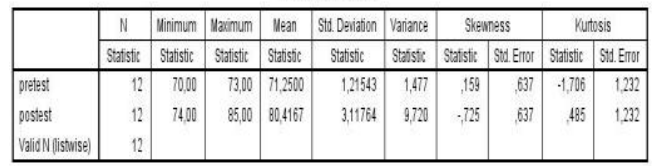


Pada tabel diatasdapat dilihat bahwa berdasarkan hasil pre test, nilai minimum untuk kelas Dosen PLS sebelum mengikuti coaching clinic sebesar 70,00, kemudian nilai maksimum sebesar 73,00. Nilai ratarata yang diperoleh yaitu 71,25 dengan nilai statistik standar deviasi sebesar 1,21. Sedangkan nilai post test yang diperoleh setelah Dosen PLS mengikuti coaching clinic yang dimulai dari materi di kelas hingga bimbingan jarak jauh dengan instruktur, maka nilai yang diperoleh yaitu nilai minimum sebesar 74,00, kemudian nilai maksimum sebesar 85,00 . Nilai ratarata yang diperoleh yaitu 80,41 dengan nilai statistik standar deviasi sebesar 3,11.Hal ini menunjukkan bahwa terdapat peningkatan kemampuan Dosen PLS dalam penulisan artikel ilmiah yang meliputi kemampuan berpikir, menganalisa, menulis dan kemampuan mereview.

Tabel 4. Paired Samples Statistics

\begin{tabular}{|c|c|c|c|c|c|}
\hline \multicolumn{6}{|c|}{ Paired Samples Statistics } \\
\hline & & Mean & N & Std. Deviation & $\begin{array}{l}\text { Std. Error } \\
\text { Mean }\end{array}$ \\
\hline \multirow[t]{2}{*}{ Pair 1} & pretest & 71,2500 & 12 & 1,21543 & 35086 \\
\hline & postest & 80,4167 & 12 & 3,11764 &, 89999 \\
\hline
\end{tabular}

Tabel 5. Paired Samples Correlations

\begin{tabular}{|l|r|r|c|} 
Paired Samples Correlations \\
\begin{tabular}{|lr|r|r|}
\hline & \multicolumn{1}{|c|}{ N } & Correlation & \multicolumn{1}{c|}{ Sig. } \\
\hline Pair 1 pretest \& postest & 12 &, 642 &, 024 \\
\hline
\end{tabular}
\end{tabular}

Tabel 6. Paired Samples Test

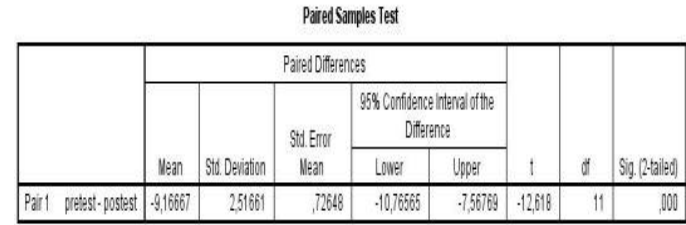

dilihat bahwa nilai rata-rata yang diperoleh Dosen PLS setelah mengikuti coaching clinic lebih tinggi jika dibandingkan dengan nilai rata-rata yang diperoleh Dosen PLS sebelum mengikuti coaching clinic. Pada perhitungan Uji $t$ didapatkan nilai statistik $t_{\text {Hitung }}=-$ 12.61; sedangkan $\mathrm{t}_{\text {Tabel }}$, yaitu $\mathrm{t}_{\mathrm{df}=11 \text {; }}$ $\propto=0,05=2,20$. Hal ini berarti bahwa $t_{\text {Hitung }}>\quad t_{d f=29 ;} \quad \propto=0,05 . \quad$ Dengan demikian, dapat dikatakan bahwa secara statistik kedua nilai rata-rata tersebut adalah berbeda nyata. Hal ini berarti pada post-test, nilai ratarata yang diperoleh dosen PLS setelah mengikuti coaching clinic lebih tinggi dari nilai rata-rata yang diperoleh dosen sebelum mengikuti coaching clinic. Oleh karena itu, dapat dikemukakan bahwa selain dapat meningkatkan kemampuan dalam penulisan artikel ilmiah, pelaksanaan coaching clinic yang dilakukan dapat membantu Dosen PLS untuk meningkatkan kemampuan berpikir, menganalisa, menulis dan melakukan review sehingga dapat menambah kuantitas dan kualitas artikel ilmiah yang dapat diterbitkan pada jurnal terakreditasi. 


\section{PENUTUP}

\section{Kesimpulan}

Berdasarkan hasil test selama penelitian, pelaksanaan coaching clinic, dan analisis terhadap pretest dan post test serta melihat dari kuantitas maupun kualitas tulisan artikel ilmiah yang dilakukan Dosen PLS FIP dapat diambil kesimpulan sebagai berikut:

1. Kemampuan Dosen PLS FIP Unimed meningkat terutama dalam kemampuan berpikir, menganalisa, menulis dan kemampuan mereview dalam proses penulisan artikel ilmiah sebelum mengikuti coaching clinic.

2. Kemampuan Dosen PLS FIP Unimed dalam proses penulisan artikel ilmiah setelah mengikuti coaching clinic secara signifikan berbeda

3. Nilai rata-rata hasil post test Dosen PLS FIP setelah mengikuti Coaching Clinic secara signifikan lebih tinggi dibandingkan dengan sebelum Dosen PLS mengikuti coaching clinic penulisan artikel ilmiah.

4. Terjadi peningkatan kemampuan penulisan artikel ilmiah pada Dosen PLS yang dapat dilihat nilai nilai rata-ratayang lebih besar pada post test yaitu setelah mengikut coaching clinic, kuantitas dan kualitas artikel ilmiah serta jurnal yang dihasilkan Dosen PLS FIP lebih tinggi dibandingkan sebelum mengikuti coaching clinic penulisan artikel ilmiah.

\section{Saran}

Keberhasilan dalam pelaksanaan coaching clinic penulisan artikel ilmiah pada Dosen PLS FIP Unimed dapat menjadi salah satu alternatif untuk meningkatkan motivaasi dan kemampuan dosen dalam menulis karya ilmiah / artikel yang diterbitkan pada jurnal nasional terakreditasi maupun jurnal internasional bereputasi. Berdasarkan hasil penelitian ini maka saran yang diajukan adalah sebagai berikut:

1. Dengan penelitian ini, diharapkan kemampuan dosen dapat meningkatuntuk menghasilkan karya ilmiah / artikel ilmiah sehingga dapat meningkatkan kuantitas dan kualitas artikel ilmiah Dosen PLS FIP yang dapat diterbitkan pada jurnal nasional maupun jurnal internasional bereputasi

2. Bagi dosen, penelitian ini dapat memberikan motivasi untuk terus melakukan peningkatan kemampuan berpikir, menganalisa, menulis dan mereview untuk menghasilkan karya ilmiah yang berkualitas dan berguna bagi masyarakat.

3. Bagi peneliti lain, disarankan agar dalam melakukan penelitianlebih memperhatikan variabel lain yang 
berpengaruhuntuk peningkatan kuantitas dan kualitas artikel ilmiah dosen.

\section{DAFTAR PUSTAKA}

Arifin, Zaenal. 2004. Dasar-Dasar Penulisan Karya Ilmiah. Jakarta: Gramedia.

Hamalik Oemar. 2005. Manajemen Pelatihan Ketenagakerjaan; Pendekatan Terpadu. Jakarta: Bumi Aksara

Kamil, Mustofa. 2010. Model Pendidikan Dan Pelatihan. Bandung: Alfabeta

Kamil, Mustofa. 2011. Model Pendidikan Dan Pelatihan (Konsep Dan Aplikasi). Bandung: Alfabeta

Republik Indonesia. 2005. UndangUndang Nomor 14 Tahun 2005 Tentang Guru dan Dosen

Setyosari, Punaji. 2013. Metode Penelitian Pendidikan Dan Pengembangan. Jakarta: Prenadamedia Group

Tindaon, Yosi Abdian. 2012. Pengertian Kemampuan Menulis. Dimuat dalam. 